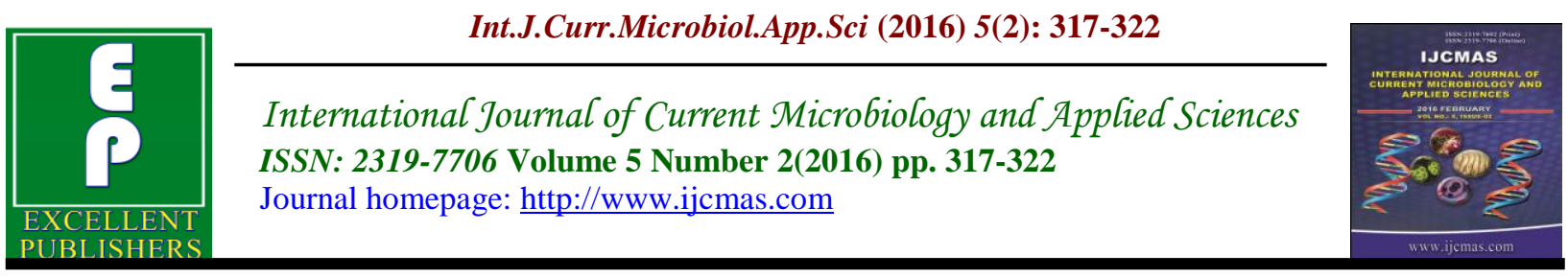

Original Research Article

doi: http://dx.doi.org/10.20546/ijcmas.2016.502.036

\title{
Anti-diabetic Profile of Extract, Kolaviron, Biflavonoids and Garcinoic acid from Garcinia kola seeds
}

\author{
M.K. Tchimene ${ }^{1 *}$, A. O. Anaga ${ }^{2}$, C.E.C. Ugwoke ${ }^{3}$, O.J. Onoja ${ }^{1}$, \\ C. O. Ezugwu ${ }^{3}$, C. Okunji ${ }^{1}$ and M.M. Iwu ${ }^{1}$ \\ ${ }^{1}$ International Centre for Ethnomedicine and Drug Development, 110 Aku Road, \\ Nsukka, Nigeria \\ ${ }^{2}$ Department of Veterinary Physiology and Pharmacology, Faculty of Veterinary \\ Medicine, UNN, Nsukka, Nigeria \\ ${ }^{3}$ Department of Pharmacognosy and Environmental Medicine, UNN, Nsukka, Nigeria \\ *Corresponding author
}

\begin{tabular}{|c|c|}
\hline & A B S T R A C T \\
\hline Keywords & \multirow{4}{*}{$\begin{array}{l}\text { Diabetes mellitus is the most common endocrine disorder that impairs glucose } \\
\text { homeostasis resulting in severe diabetic complications including retinopathy, } \\
\text { angiopathy, nephropathy, and neuropathy and causing neurological disorders due to } \\
\text { perturbation in utilization ofglucose. In the present study diabetes was induced in } \\
\text { albino rat models with alloxan monohydrate. Garcinia kola seeds, has beenclaimed } \\
\text { to possess antidiabetic properties by many investigators. The present study was } \\
\text { undertaken to screen the hypoglycemic activityof ethanol extract, the fraction and } \\
\text { compounds of } G \text {. kola seeds. The results showed thatthe extract, fraction, } \\
\text { compounds and the reference drug (glibenclamide) showed different levels of } \\
\text { antidiabetic effect. However, GB2 gave the best antidiabetic effect which is an } \\
\text { improvement from that of the extract. The effect of GB2 was similar to } \\
\text { glibenclamide. }\end{array}$} \\
\hline $\begin{array}{l}\text { Alloxan, } \\
\text { Diabetes } \\
\text { mellitus, } \\
\text { Garcinia kola, } \\
\text { Blood glucose. }\end{array}$ & \\
\hline Artic & \\
\hline $\begin{array}{l}\text { Accepted: } \\
\text { 18 January } 2016 \\
\text { Available Online: } \\
\text { 10, February } 2016\end{array}$ & \\
\hline
\end{tabular}

\section{Introduction}

Bitter Kola also known as Garcinia kola is a tropical flowering plant found in western and central Africa and it produces brown, nut-like seeds. It has been used in African culture for centuries for both traditional and medicinal purposes. It contains dimeric flavonoid, lipase inhibitor which is believed to have many healing benefits. Bitter Kola is a masticatory used in traditional hospitality, cultural and social ceremonies such as naming ceremonies and weddings.
Bitter kola is used in many tropical countries to fight infectious diseases such as AIDS and the Ebola virus. It has shown to possess anti-inflammatory, antimicrobial and antiviral properties. It is often used to treat the symptoms of colds. It is particularly very effective for coughs, nasal congestions and help coagulate phlegm. It is also effective in alleviating sore throat, is sometimes believed to cure impotence. It increases blood flow to the Core area in men who 
have hardening of the arteries. Garcinia kola has been successfully used to treat patients suffering from knee osteoarthritis. It reduced pain and swelling and improved movement. Garcinia kola is known for its antiinflammatory and antioxidant properties. It is used to prevent infections and viruses, especially of the immune system. Bitter Kola has been known to be a natural hunger suppressant and also increases the urge to drink more water. It is used as a substitute for hops in brewing lager beer. It is especially useful in preventing beer spoilage (Iwu, 2003, Iwu et al.,1982). This study was to investigate the antidiabetic property of the crude extract of Garcinia kola and the isolates (kolaviron, GB1, GB2 and garcinoic acid).

\section{Materials and Methods}

\section{General Experimental Procedures}

The UV spectra were obtained with a shimadzu 3101 PC instrument and IR spectra determined with a jasco FT-IR 410 apparatus. ${ }^{1} \mathrm{H}(400.6 \mathrm{MHz})$ and ${ }^{13} \mathrm{C}(100.13$ $\mathrm{MHz}) \mathrm{nmr}$ spectra were recorded in $\mathrm{CDC}_{13}$ (with its signals at $\delta 7.25$ and $77.0 \mathrm{ppm}$ as reference) TLC was carried out on silica gel $60 \mathrm{GF}_{254}$ pre-coated plates with detection by UV light or by spraying with $50 \% \mathrm{H}_{2} \mathrm{SO}_{4}$ followed by heating at $100^{\circ} \mathrm{C}$.

\section{Plant Material, Preparation of Extract, Fractions and Compounds}

Garcinia kola seeds were collected within the surrounding of Orba, Nsukka, Enugu State, Nigeria in March 2010, Nigeria, and was identified and authenticated by Mr. Alfred Ozioko of International Centre for Ethnomedicine and Drug Development. The voucher specimen (INTERCEDD 022010) is deposited at the same center.
The air-dried and powdered plant material $(5 \mathrm{Kg})$ was macerated in a mixture of $\mathrm{CH}_{2} \mathrm{Cl}_{2}-\mathrm{MeOH}$ (1:1) for 48h. Removal of the solvent in vacuo in a rotary evaporator provided an organic extract $(600 \mathrm{~g})$.

Kolaviron was isolated according to Iwu et al. 1990as modified by Farombi et al. 2000. Briefly, the powdered seeds were extracted with light petroleum ether (b.pt 40-60 o C) in a soxhlet for $24 \mathrm{~h}$. The defatted, dried marc was repacked and extracted with acetone $\left(\mathrm{Me}_{2} \mathrm{CO}\right)$. The extract was concentrated and diluted twice its volume with water and extracted with ethyl acetate. The concentrated ethyl acetate fraction gave a yellow solid known as Kolaviron (TGA)

Further purification of TGA (203.5g) using silica gel as stationary phase and mixture of $\mathrm{CH}_{2} \mathrm{Cl}_{2} /$ actone afforded $\mathrm{GB} 1(68,1 \mathrm{~g})$ and GB2 $(101,6 \mathrm{~g})$. The fraction obtained with EtOAc/nhex (8:2) was further purified using silica gel as stationary phase and EtOAc/nhex mobile phase yielded garcinoic acid (TGK3, 107,3g).

\section{Identification of GB1, GB2 and TGK3}

The know compounds GB1, GB2 and garcinoic acid were identified by comparison of NMR data with published data (Kenji et al., 1997).

\section{Experimental Animals}

Thirty five (35) white albino Wistar rats (86 - $100 \mathrm{~g}$ ) of either sex were procured from the Laboratory Animal Unit of the Faculty of Veterinary Medicine, University of Nigeria, Nsukka. They were kept in stainless steel cages and were fed ad-libitum with standard laboratory animal feed (Guinea Feed $\left.{ }^{\circledR}\right)$, except in situations, where fasting was required. They were also provided with clean tap water. They were maintained in 
accordance with the recommendation in the Guide for the Care and Use of Laboratory Animals (DHHS, NIH Publication No. 8523, 1985). They were allowed 2 weeks to acclimatize before the start of the experiments.

\section{Brine Shrimps Lethality Test}

The effect of the extract on brine shrimps was evaluated using the method of Mclaughlin et al 1991. Briefly, brine shrimp eggs were hatched in culture tank containing sea water under bright light for $48 \mathrm{~h}$. Ten nauplii were counted into bijou bottles in triplicates and were incubated with graded concentrations of the extract $(10,100$ and $1000 \mathrm{ppm}$ ) at room temperature for $24 \mathrm{~h}$. The mean surviving nauplii was determined for each concentration of the extract and compared with that of the control. The result was analyzed using probit analysis (minitab for windows release 12.21) to determine the $\mathrm{LC}_{50}$ at $95 \%$ confidence interval.

\section{Chemicals}

Alloxan monohydrate, a most widely used chemical diabetogen was procured from Loba chemie, Mumbai, India and other reagents used in the experiment were of analytical grade. Chemically alloxan is 2, 4, 5,6 tetra oxo hexahydro pyrimidine. Glibenclamide, a standard antidiabetic agent was purchased from Sigma, Jos, Nigeria.

\section{Antihyperglycaemic Studies Induction of Diabetes}

Hyperglycaemia was induced in overnight fasted adult Wistar strain albino rats weighing $180-240 \mathrm{~g}$ by a single intraperitoneal injection of freshly prepared alloxan monohydrate in normal saline (200 $\mathrm{mg} / \mathrm{kg}$ body weight) in a volume $1 \mathrm{ml} / \mathrm{kg}$ body weight (Kastumata et al., 1999). Hyperglycaemia was confirmed by the elevated glucose level in plasma, determined at $48 \mathrm{~h}$ after injection (Mandal et al., 1997). The rats found hyperglycaemic were screened for the antihyperglycaemic study.

\section{Experimental Design}

Animals were divided into six groups (A-F) of five rats each. Test groups were administered samples (crude extract, kolaviron, GB1, GB2 and garcinoic acid) at dose of $50 \mathrm{mg} / \mathrm{kg}$ body weight by oral route. Standard and control animals were treated with standard drug glibenclamide at an oral dose of $5 \mathrm{mg} / \mathrm{kg}$ body weight and distilled water respectively. All doses were started 48 $h$ after alloxan injection. Fasting blood glucose levels were estimated on Hour 0,1 , 3 , and $6 \mathrm{~h}$ post treatment.

\section{Statistical Analysis}

Data were statistically calculated by utilizing one-way ANOVA and expressed as mean \pm S.E.M. followed by Dunnett's $t$-test using computerized GraphPad InStat version 3.05, Graph pad software, U.S.A.

\section{Results and Discussion}

Pancreas is the primary organ involved in sensing the organism's dietary and energetic states via glucoseconcentration in the blood and in response to elevated blood glucose, insulin is secreted[9]. Alloxan is one of the usual substances used for the induction of diabetes mellitus apart from streptozotocin. Alloxan has a destructive effect on the beta cells of the pancreas(Prince et al.,2000; Jelodar et al. 2003).

Alloxan causes a massive reduction in insulin release bythe destruction of b-cells of the islets of langerhans, thereby inducing hyperglycaemia (Grover et al. 2000) Insulin deficiencyleads to various metabolic alterations in the animals viz increased 
blood glucose, increased cholesterol, increased levels of alkaline phosphate and transaminases (Shammugasundraram et al. 1983; Begum et al. 1978).

The results of the present study indicate that the ethanol extract of $G$. kola seeds, kolaviron, garcinoic acid, GB1, GB2 and the reference drug (glibenclamide) showed different levels of antidiabetic effect in aminals made diabetic with alloxan. However, GB2 gave the best antidiabetic effect which is an improvement from that of the crude extract. The effect of GB2 was similar to glibenclamide (table 1).

Alloxan has been shown to induce free radical production and cause tissue injury. The pancreas is especially susceptible to the action of alloxan induced free radical damage.

The activity of the extract and the kolaviron is related to presence of bioflavonoids in $\mathrm{G}$. kola seed. Bi-flavonoids comprise a group of phenolic secondary plant metabolites that are widespread in nature. Major flavonoids that have well categorized structure and well defined structure function relationships are: flavans, flavanones, flavones, flavonols, flavanonols, cetechins anthocyanidins and isoflavones. Bio-flavonoids are well known for their multi-directional biological activities including antidiabetic efficacy (Brahmachari, 1978; 2008) Numerous studies have been carried out to explore their potential role in the treatment of diabetes (Jung et al,, 2008; Matsui et al.,2006; Qi et al, 2010). A good number of studies have already demonstrated the hypoglycemic effects of flavonoids using different experimental models and treatments.

In conclusion, from this study, we can state that the Ethanolic extract, kolaviron and GB1 of G. kola have beneficial effects on blood glucose levels as well as improving hyperlipidemia and other metabolic aberrations. Further pharmacological and biochemical investigations will clearly elucidate the mechanism of action and will be helpful in projecting this plant as a therapeutic target in diabetes research.

Table.1 Effects of the Crude and Fractions of Garcinia cola on Alloxan-induced hyperglycaemia (Antidiabetic Assay)

\begin{tabular}{|l|c|c|c|c|c|c|}
\cline { 2 - 7 } \multicolumn{2}{|c|}{} & \multicolumn{3}{l|}{$\begin{array}{l}\text { Mean Blood glucose level } \pm \text { SEM } \\
\text { interval (h) }\end{array}$} \\
\hline Drug/Fractions & Dose(mg/kg) & FBS b4 induction & 0 & 1 & 3 & 6 \\
\hline Glibenclamide & 5 & $2.8 \pm 0.27$ & $14.23 \pm$ & $8.74 \pm$ & $4.44 \pm$ & $2.27 \pm$ \\
& & & 2.11 & 3.21 & 0.78 & 0.54 \\
\hline Crude & 50 & $3.1 \pm 0.17$ & $13.97 \pm$ & $6.03 \pm$ & $5.27 \pm$ & $3.77 \pm$ \\
& & & 2.61 & 2.26 & 1.74 & 1.20 \\
\hline TGA2 & 50 & $1.8 \pm 0.11$ & $14.6 \pm$ & $9.87 \pm$ & $8.3 \pm$ & $8.5 \pm$ \\
& & & 0.98 & 4.45 & 3.31 & 3.02 \\
\hline TGK3A & 50 & $3.4 \pm 0.31$ & $12.93 \pm$ & $7.93 \pm$ & $5.3 \pm$ & $5.8 \pm$ \\
& & & 1.64 & 1.31 & 0.22 & 0.33 \\
\hline GB1 & 50 & $3.2 \pm 0.25$ & $14.1 \pm$ & $10.03 \pm$ & $9.37 \pm$ & $6.33 \pm$ \\
& & & 3.01 & 5.21 & 5.35 & 3.52 \\
\hline GB2 & 50 & $3.5 \pm 0.11$ & $13.5 \pm$ & $7.1 \pm$ & $7.57 \pm$ & $2.6 \pm$ \\
& & & 2.83 & 2.96 & 2.96 & 0.37 \\
\hline
\end{tabular}


Figure.1 Structures<smiles>[R6]c1cc(C2CC(=O)c3c(O)cc(O)c(CC4C(=O)c5c(O)cc(O)cc5OC4c4ccc(O)cc4)c3O2)ccc1Br</smiles>

GB1, R1= OH, R2=H

GB2, $\mathrm{R} 1=\mathrm{R} 2=\mathrm{OH}$

TGA2= Kolaviron

Crude $=$ Ethanolic extract of Garcinia kola seeds

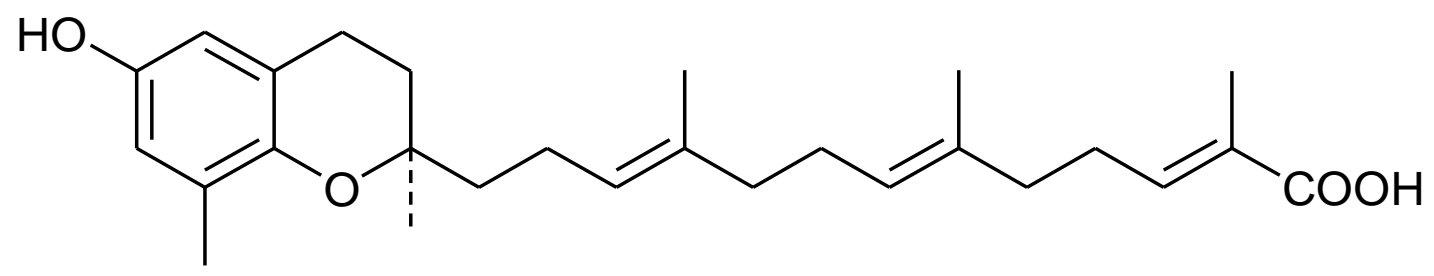

TGK3= Garcinoic acid

\section{Acknowledgement}

The authors thank the Bioresources Development and Conservation Program (BDCP), for financial support.

\section{References}

Begum N., Shanmugasudnaram K.R., 1978. Tissue phosphates in experimental diabetes, Arogya: J. Health Sci. 4,129139.

Brahmachari, G., 2008 Naturally occurring flavanones: An overview. Nat. Prod. Commun. 3,1337-1354.

Brahmachari, G., 2009. In Natural Products: chemistry, biochemistry and pharmacology, G. Brahmachari, Ed., Narosa, publishing House Pvt Ltd. New Delhi; Pp.1-20.
Edem D.O., 2009.Hypoglycemic Effects of Ethanolic Extracts of Alligator Pear Seed (Persea Americana Mill) in Rats, European Journal of Scientific Research. 33(4): 669-678.

Grover J.K., Vats V., Rathi S.S., 2000. Antihyperglycemic effect of Eugenia jambolana and Tinospora cordifolia in experimental diabetes and their effects on key metabolic enzymes involved in carbohydrate metabolism. J. Ethnopharmacol. 73,461-470.

Farombi E.O., Tahntenyg D.G., Agboola A.O., Nwankwo J.O. and Emerole G.O., 2000 Food and Chem Toxicol. 38 (6), $535-541$.

Iwu M.M, and Igboko O., 1982, Flavonoids of Garcinia kola seeds, J. Nat. prod. 45, 650-651.

Iwu M.M., 2014. Handbook of African 
Medicinal plants. CRC Press, Boca Raton, Florida.

Iwu M.M., Igboko O.A., Elekwa O.K. and Tempesta M.S., 1990. Prevention of thioacetamide-induced hepatotoxicity by biflavanones of Garcinia kola. Phytotherapy Research 4,157 - 159.

Jelodar G., Mohsen M., Shahram S., 2003. Effect of walnut leaf, coriander and pomegranate on blood glucose and histopathology of pancreas of alloxan - induced diabetic rats, African $\mathrm{J}$. Traditional, Complementary and Alternative Medicines 3, 299 - 305.

Jung, M., Park M., Lee H. C., Kang Y.H., Kang E.S., Kim S.K. 2006. Antidiabetic agents from medicinal plantsCurr. Med. Chem. 13, 12031218 .

Kastumata K, Kastumata Y, Ozawa T, Kastumata K., 1999. Potentiating effect of combined usage of three sulfonylurea drugs on the occurrence of alloxan diabetic rats. Hormone Metab Res.25:125-6.

Kenji T., Tomoyuki S., Miho T., Mohammad A., John A.A. and Masatake N., 1997. Constituents of Garcinia kola. Two new antioxidants, Garcinoic acid and Garcinal. Heterocyles. 45 (8), 1559-1566.

Mandal S.C., Mukharjee P.K., Saha K., Das J., Pal M., Saha B.P., 1997. Hypoglycemic activity of Ficus racemosa L. (Moraceae) Leaves in streptozotocin induced Diabetic Rats. Nat Prod Sci. 3, 38-41.

Matsui, T., Ogunwande I. A. Abesundara K. J. M., 2006. Matsumolo K. Antihyperglycemic potential of products. Mini-rev. Med. Chem. 6:109-120.

McLaughlin J.L., Chang C.J., Smith D.L. 1991 "Bench-top" bioassays for the discovery of bioactive natural products: an update. In: Rahman A, ed., Studies in Natural Product Chemistry 9, Elsevier, Amsterdam, Pp. 383-409.

Prince S.M., Menon V.P., 2000. Hypoglycemic and other related actions of Tinospora cardifolia roots in alloxan induced diabetic rats, $J$. Ethnopharmacol. 70, 9-15.

Qi L.W., liu E.H, Chu, C., Peng Y.B. Cai H.Y, Li P., 2010. Anti-diabetic agents from natural products-an update from 2004-2009. Curr.Top. Med. Chem.10, 434-457.

Shanmugasundaram K.R, Panneerselvam S.P., Shanmugasundaram E.R.B., 1983. Enzyme changes and glucose utilization in diabetic rabbit, the effect of Gymnema sylvestrae, R. Br. J. Ethnopharmacol. 7, 205-216.

\section{How to cite this article:}

M.K. Tchimene, A. O. Anaga, C.E.C. Ugwoke, O.J. Onoja, C. O. Ezugwu, C. Okunji1 and M.M. Iwu. 2016. Anti-diabetic Profile of Extract, Kolaviron, Biflavonoids and Garcinoic acid from Garcinia kola seeds. Int.J.Curr.Microbiol.App.Sci. 5(2): 317-322. doi: http://dx.doi.org/10.20546/ijcmas.2016.502.036 